\title{
Drosera indica as an indoor biological control against mosquitoes
}

\author{
Alma E. Nacua * and Noami D. Solano \\ College of Arts and Sciences, Universidad de Manila, One Mehan Garden Ermita Manila, Philippines.
}

Publication history: Received on 13 December 2020; revised on 20 December 2020; accepted on 22 December 2020

Article DOI: https://doi.org/10.30574/gscarr.2020.5.3.0126

\begin{abstract}
In the wild, carnivorous plants obtain some nutrients by trapping and digesting various invertebrates, and occasionally even small frogs and mammals. Because insects are one of the most common prey items for most carnivorous plants, they are sometimes called insectivorous plants The aim of this study is to identify Drosera indica indeed a carnivorous plant to control indoor mosquitoes in Metro Manila. Experimental Method of research. Controlled pot plant were placed in the Urban garden of UDM and observed to trapped insects. Another pot plant was placed inside the room that verified attracted insects. The Experimental period runs for 7 days from October 5 to 11, 2020. Conclusion: Based on the results and finding, Drosera indica is an insectivorous plant that preys on Aedes aegypti and Anopheles mosquitoes
\end{abstract}

Keywords: Drosera indica; Aedes aegypti

\section{Introduction}

Dengue fever is the most important mosquito-borne viral disease in the world WHO (2013). Dengue is a viral disease transmitted primarily by female mosquitoes from the species Aedes aegypti. It is considered as the most common arbovirus (arthropod-borne virus) infection globally, with transmission occurring in at least 128 countries and almost 4 billion people at risk 0.J. Brady et al (2012). The number of dengue cases reported annually to the World Health Organization (WHO) has increased significantly from an average of less than a thousand cases globally in the 1950s to more than 3 million cases in 2015 WHO (2016). However, there has been a substantial under-reporting of dengue within the health systems and to WHO M. E Beatty et al (2011) which greatly underestimate the apparent global incidence rate estimated at about 50-100 million symptomatic cases per year S. Bhatt (2013), M. Castro et al (2017), JD. Stanaway (2013). The transmission of dengue viruses is influenced by population growth, urbanization, inadequate public health infrastructure, poor solid waste management, environmental risk factors and inconsistent preventive practices, among others. Dengue virus (DENV) has four different serotypes and thus a person can be infected more than once J.G. Rigau-Pérez (2006). Moreover, dengue can evolve into a more complex form of a disease known as dengue hemorrhagic fever (DHF) or dengue shock syndrome, first recognized in the 1950s during dengue epidemics in the Philippines and Thailand J.G. Rigau-Pérez (2006). which can be fatal K. Clyde (2006) In the Philippines, epidemic dengue is considered one of its eight pervasive infectious diseases DOH 2011 From 2008 to 2012, the country's Department of Health (DOH) reported 585,324 dengue cases, with a case fatality rate (CFR) of $0.55 \%$ or 3195 deaths [14] and ranks fourth in the number of dengue cases among the 10 Association of Southeast Asian Nations (ASEAN) D.S. Shepard (2013), E.A. Undurraga (2013). In the wild, carnivorous plants obtain some nutrients by trapping and digesting various invertebrates, and occasionally even small frogs and mammals. Because insects are one of the most common prey items for most carnivorous plants, they are sometimes called insectivorous plants. It is not surprising that the most common habitat for these plants is in bogs and fens, where nutrient concentrations are low but water and sunshine seasonally abundant. Whether aquatic or terrestrial, carnivorous plants have a basically similar ecology. Species of two or three

\footnotetext{
* Corresponding author: Alma E. Nacua

College of Arts and Sciences, Universidad de Manila, One Mehan Garden Ermita Manila, Philippines.
} 
genera (e.g., Sarracenia, Drosera, and Pinguicula) are often found growing almost side by side. The majority are most likely to be found in damp heaths, bogs, swamps, and muddy or sandy shores where water is at least seasonally abundant and where nitrogenous materials are often scarce or unavailable because of acid or other unfavorable soil conditions Britanica.com. Many carnivorous plants have special glands that secrete enzymes powerful enough to penetrate the hard exoskeleton of insects so they can absorb nutrients from inside their prey. Carnivorous plants instead draw nitrogen, phosphorus, and other critical nutrients from their prey in order to build light-harvesting enzymes. Eating animals, in other words, lets carnivorous plants do what all plants do: grow by grabbing energy directly from the sun CARL ZIMMER (2010).

\section{Material and methods}
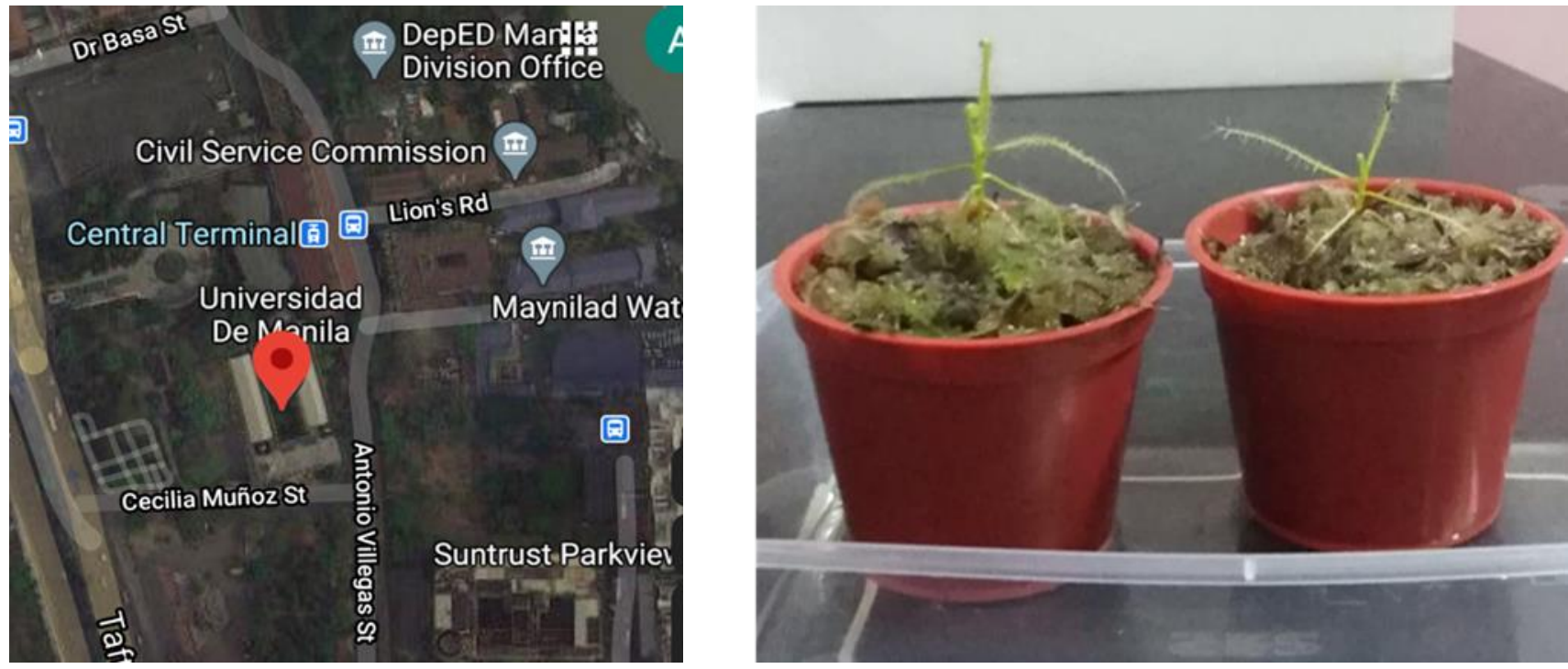

Figure 1 Google map of Universidad de Manila (UDM) with the coordinates of 14.591587, 120.981126

(Google earth) at the left image, the set-up of Drosera indica to catch mosquitoes

Experimental Method of research we used in this study, Controlled pot plant were placed in the Urban garden of UDM and observed to trapped insects. Another pot plant was placed inside the room that verified attracted insects. Drosera indica (Droseraceae) were purchased in the insectivorous plant shop online. This shop cultivates insectivorous plants through tissue culture or by seeds. The researcher made it sure not to collect this plants in the highland forest to preserve and conserve the diversity of this plant species. The Experimental period runs for 7 days from October 5 to 11 , 2020.

\section{Results}

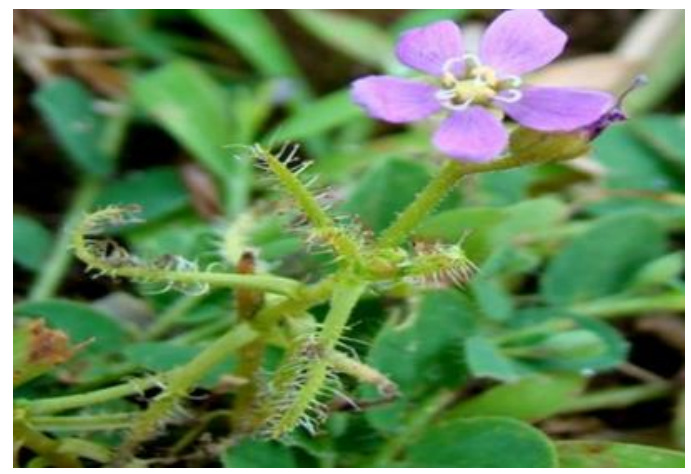

Figure 2 Drosera indica in the wild with trapped ants

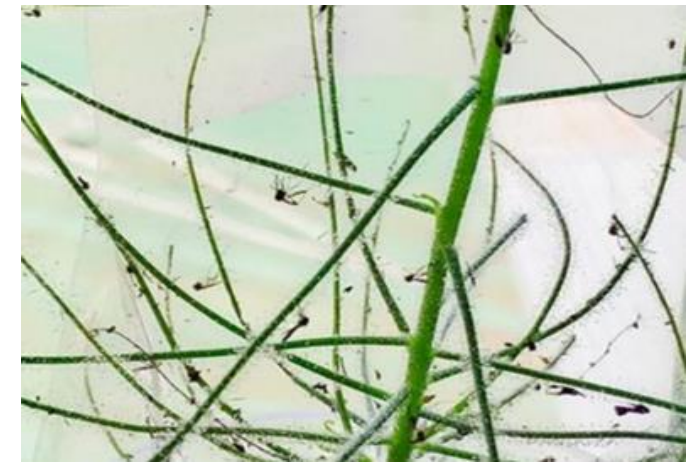

Figure 3 Drosera indica at UDM garden with mosquitoes 

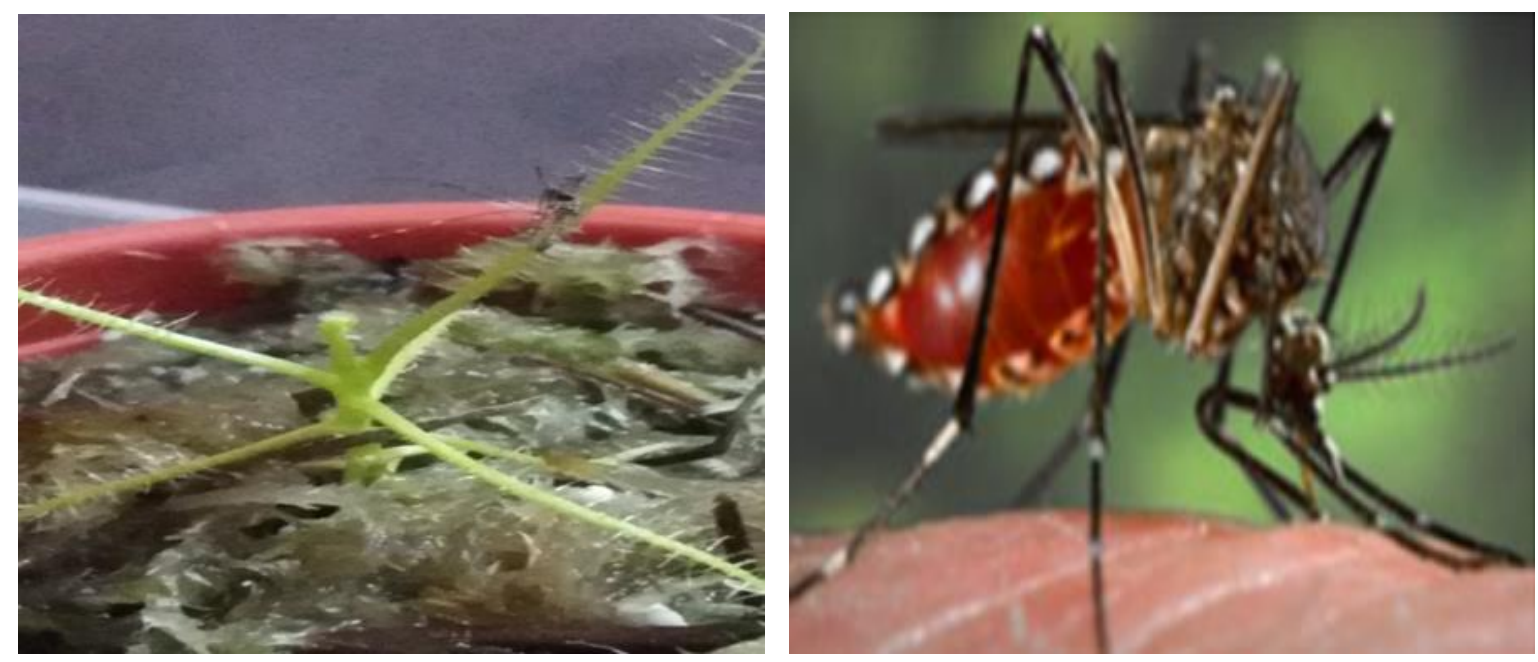

Figure 4 Aedes aegypti, note the typical white markings on the legs Nacua et al 2020

Figure 4 Drosera indica with trapped species of Aedes aegypti, can be recognized by white markings on its legs and a marking in the form of a lyre on the upper surface of its thorax. Aedes aegypti, the yellow fever mosquito, is a mosquito that can spread dengue fever, chikungunya, Zika fever, Mayaro and yellow fever viruses, and other disease agents. Aedes aegypti is a day biting mosquito. That means that the mosquito is most active during daylight, for approximately two hours after sunrise and several hours before sunset. The mosquito rests indoors, in closets and other dark places. Outside, they rest where it is cool and shaded. The males of all species of mosquitoes do not bite humans or animals of any species, they live on fruit. The female of Aedes aegypti feed not only on fruit, but also on blood. When viewed under a microscope, male mouthparts are modified for nectar feeding, and female mouthparts are modified for blood feeding (see figure 2). The female needs blood to mature her eggs. Feeding on humans generally occurs at one to two hour intervals. The mosquito attacks generally from below or behind, usually from underneath desks or chairs and mainly at the feet and ankles. Aedes aegypti is adapted to breed around human dwellings and prefers to lay its eggs in clean water which contains no other living species. These eggs become adult in about one-and-a-half to two weeks. In dengue virus infected mosquito's, the virus is present in the salivary glands of the mosquito. When a female Aedes aegypti bites a human for food, she injects saliva into the wound where the anti-coagulants contained in her saliva facilitate feeding. Without knowing, the mosquito also injects the dengue virus into the host. Since the virus can be passed from adult to egg, the dengue virus is guaranteed to survive until the next summer and heavy rains. Dengue virus net.com

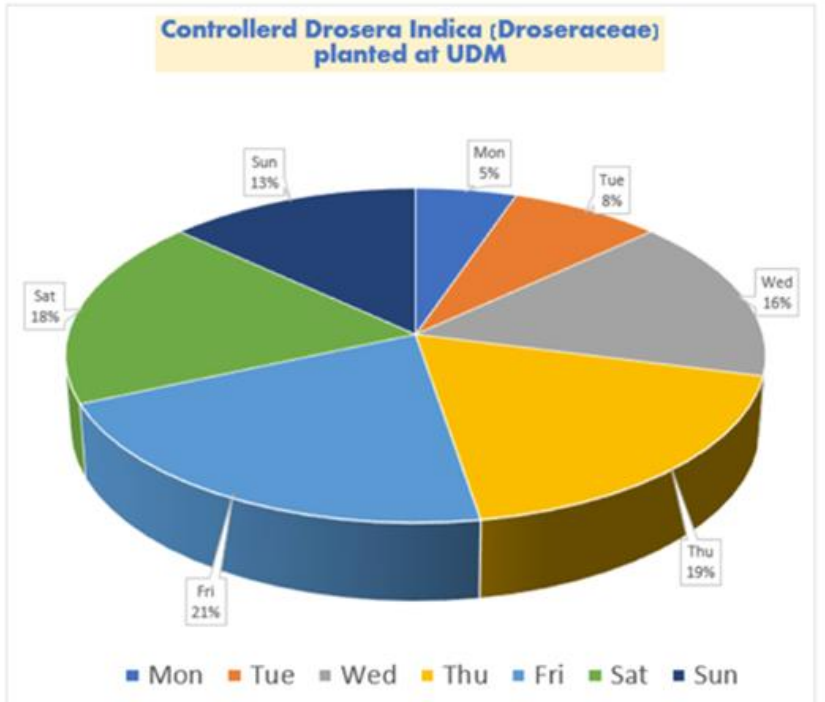

\begin{tabular}{|c|c|c|}
\hline Day & No. of Mosquito - & Description \\
\hline Monday & 2 & Aedes aegypti \\
\hline Tuesday & 3 & Aedes Aegypti \\
\hline Wednesday & 6 & Anopheles Mosquitoes \\
\hline Thursday & 7 & Anopheles Mosquitoes \\
\hline Friday & 8 & Anopheles Mosquitoes \\
\hline Saturday & 7 & Anopheles Mosquitoes \\
\hline Sunday & 5 & Anopheles Mosquitoes \\
\hline
\end{tabular}

Figure 5 Drosera indica attracted more mosquitoes in the garden, Wednesday, Thursday, Friday, Saturday and Sunday has higher percentage of mosquitoes perhaps less people present in UDM, due to pandemic 


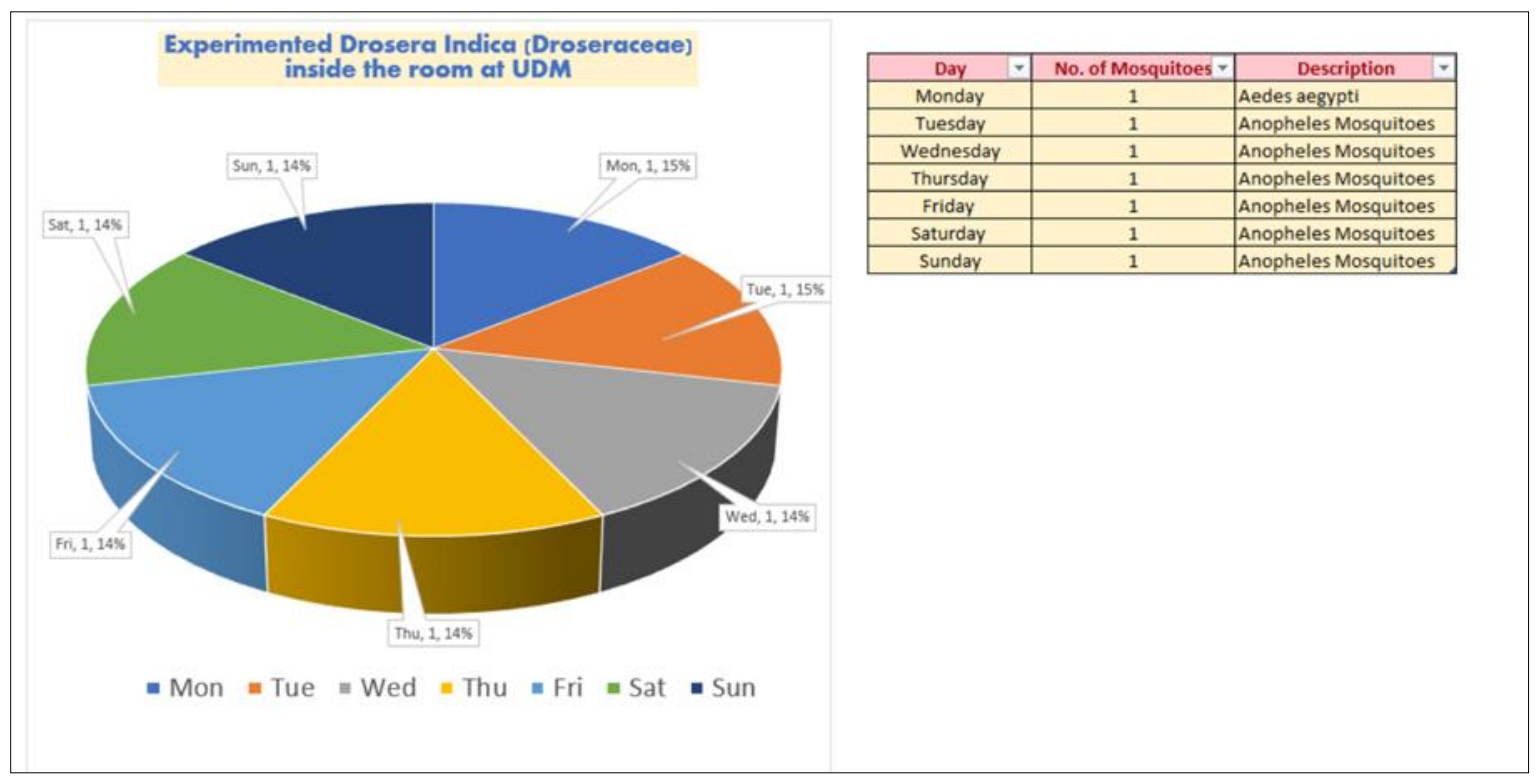

Figure 6 Drosera indica tested to trapped mosquitoes inside the room, figure shown that even inside the room there were presence of Anopheles mosquitoes and Aedes aegypti, UDM Mehan garden is a dipterocarp forest with many trees, water drainage system at the roof top of UDM, After the rain many mosquitoes thrive in the garden and enter the room when door is open.

\section{Discussion}

Drosera indica L. and D. serpens Planch have been reported as rarely occurring on the island of Luzon. The latter species has been recently separated from D. indica again (Barrett \& Lowrie 2013). Drosera indica occurs also on Culion island of Palawan province and Malalison island of Western Visayas (Planchon 1848, Merrill 1922, Croizat 1952, Barrett \& Lowrie 2013). Drosera indica is very sensitive to grow in the garden. Some actually grow in water while others need drier conditions. In the wild it is commonly found near the shoreline of the river. A soil mix of mostly or even complete sand works best. It is native to tropical countries like the Philippines throughout the world, from Asia to Africa. Drosera indica is unbranched, annual herbaceous plant, fibrous root system and can grow as high from 2 to 20 inches tall. Leaves are narrow, linear, young plants stand upright, when grew older stems tend to coil. Adult plants can be yellow to green and turns red in color under the direct sunlight. It also bears flower, color can ne white, pink, orange or purple. Stems and leaves has Trichomes which is used to catches the insects as prey. It can be propagated by means of cuttings. Matured stem can be cut and put in the water until roots comes out and re planted in a garden soil mixed with sand, and mosses, wet with mineral water or rain water. Newly propagated Drosera should at least placed indoor for 3 days, and then transfer under indirect sunlight. After 5 to 7 days it is advisable to place it under the full sun to encourage growth and development. Drosera indica in the wild were identified to trapped spiders, butterflies and moth, Aphids, and mosquitoes. In Metro Manila, it has been verified that the Drosera indica indeed an insectivorous plant since it preys on mosquitoes in the garden and inside the room with presence of Anopheles mosquitoes and Aedes aeypti. Manila is known to be over crowded city in the Philippines, and during rainy season, Dengue cases is increasing every year. With this experiment, it has documented and verified information that Drosera can be an alternative biological control for the adult mosquitoes. Drosera is an insectivorous plant that derive their nutrients through mosquitoes and other form of insects. Inside the room, mosquitoes are the nutritive organism that they can only prey on it. Which is also observed in the garden and in the wild. This was also observed by Charles Darwin in the year 1875. Carnivorous plants are plants that derive some or most of their nutrients (but not energy, which they derive from photosynthesis) from trapping and consuming animals or protozoans, typically insects and other arthropods. Carnivorous plants have adapted to grow in places where the soil is thin or poor in nutrients, especially nitrogen, such as acidic bogs. Charles Darwin wrote Insectivorous Plants, the first well-known treatise on carnivorous plants C. Darwin (1875). In general, plants absorb nitrogen and phosphorus from the soil through their roots. Insectivorous plants, however, absorb nitrogen and phosphorus from their animal prey through their leaves specially modified as traps Frank J.H. (2008). 


\section{Conclusion}

Based on the results and finding, Drosera indica is an insectivorous plant that preys on Aedes aegypti and Anopheles mosquitoes.

\section{Compliance with ethical standards}

\section{Acknowledgments}

I would to thank the UDM administration for motivating the researchers to the research for publication, to CHED for funding the research study.

\section{Disclosure of conflict of interest}

No conflict of interest

\section{References}

[1] CARL ZIMMER. Carnivorous Plant. March 2010.

[2] Coudeville B. Dervaux, O Wichmann, HS Margolis, JN Kuritsky. Health economics of dengue: A systematic literature review and expert panel's assessment, Am. J. Trop. Med. Hyg. 2011; 84: 473-488.

[3] Darwin C. Insectivorous plants. London: John Murray. 1975. 978-1-4102-0174-4.

[4] Dengue virus net.com Aedes aegypti.

[5] Department of Health. National objectives for health Philippines, 2011-2016: Health sector reform agenda monograph no. 12., Tech. Rep., Manila, Republic of the Philippines: Health Policy. 2011.

[6] Development and Planning Bureau (HPDPB), Department of Health,

[7] DS Shepard, EA Undurraga, YA Halasa. Conomic and disease burden of dengue in southeast asia, PLOS Negl. Trop. Dis. 2013; $1-12$.

[8] EA Undurraga, YA Halasa, DS Shepard. Use of expansion factors to estimate the burden of dengue in southeast asia: A systematic analysis, PLOS Negl. Trop. Dis. 2013; 1-15.

[9] Encyclopedia Britannica. April 8, 2020.

[10] Farlow TW, Scott, SI Hay. Refining the global spatial limits of dengue virus transmission by evidence-based consensus, PLoS Neglected Trop. Dis. 2012; 6: e1760.

[11] Frank JH. Insectivorous Plants. In: Capinera J.L. (eds) Encyclopedia of Entomology. Springer, Dordrecht. 2008.

[12] JD Stanaway, DS Shepard, EA Undurraga, YA Halasa, LE Coffeng, OJ Brady, SI Hay, N Bedi, IM Bensenor, CA Castaeda-Orjuela, TW Chuang, KB Gibney, ZA Memish, A Rafay, KN Ukwaja, N Yonemoto, CJL. Murray. The global burden of dengue: An analysis from the global burden of disease study 2013, Lancet Infect. Dis. 2016; 16: 712723.

[13] JG Rigau-Pérez. Severe dengue: The need for new case definitions, Lancet Infect. Dis. 2006; 297-302.

[14] JL Kyle and E Harris. Global spread and persistence of dengue, Annu. Rev. Microbiol. 2008; 62: 71-92.

[15] ME Beatty, P Beutels, MI Meltzer, DS Shepard, J Hombach, R Hutubessy, D Dessis, LM Castro, M Wilson, DE Bloom. Disease and economic burdens of dengue, Lancet Infect. Dis. 17. 2017; 70-78.

[16] N Bedi, IM Bensenor, CA Castaeda-Orjuela, TW Chuang, KB Gibney, ZA Memish, A Rafay, KN Ukwaja, N Yonemoto, CJL Murray. The global burden of dengue: An analysis from the global burden of disease study, Lancet Infect. Dis. 16. 2016; 712-723.

[17] S Bhatt, PW Gething, OJ Brady, JP Messina, AW Farlow, CL Moyes, JM Drake, JS Brownstein. World Health Organization. Global strategy for dengue and prevention and control 2012-2020. 2013.

[18] World Health organization. 2016.

[19] World Health Organization. Dengue and severe dengue fact sheet. 2017. 